\title{
Clinical Dental Care Epidemiology, Prevalence, Symptoms and Routes of Transmission of Coronavirus Disease 19: A Systematic Review of Literature and Meta-Analysis
}

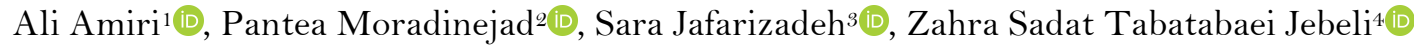

\author{
'Department of Orthodontics, College of Stomatology, The First Affiliated Stomatological Hospital, Xi'an Jiaotong University, Xi'an \\ 710004, PR China. \\ ${ }^{2}$ Iranian Association of Periodontology, Tehran, Iran. \\ ${ }^{3}$ School of Dentistry, Islamic Azad University, Tabriz Branch, Tabriz, Iran. \\ ${ }^{4}$ School of Dentistry, Azad University Isfahan (Khorasgan) Branch, Faculty of Dental, Isfahan, Iran.
}

Correspondence: Ali Amiri, Department of Orthodontics, College of Stomatology, The First Affiliated Stomatological Hospital, Xi’an Jiaotong University, Xi’an 710004, PR China. E-mail: draliamiri2020@gmail.com

Academic Editor: Alessandro Leite Cavalcanti

Received: 28 October 2020 / Review: 07 January 2021 / Accepted: 18 January 2021

How to cite: Amiri A, Moradinejad P, Jafarizadeh S, Jebeli ZST. Clinical dental care epidemiology, prevalence, symptoms and routes of transmission of coronavirus disease 19: a systematic review of literature and meta-analysis. Pesqui Bras Odontopediatria Clín Integr. 2021; 21:e0229. https://doi.org/10.1590/pboci.2021.079

\begin{abstract}
Objective: To evaluate the epidemiological evidence, symptoms, and transmission routes of Coronavirus Disease 19 for clinical dental care. Material and Methods: PubMed, Embase, ISI, Scopus, Medicine have been used to search for articles until October 2020. Therefore, EndNote X9 was used to manage electronic resources. A 95\% confidence interval (CI) effect size, random effect model, and the REML method were evaluated. Forty-one articles were found. In the first step of selecting studies, 40 studies were selected to review the abstracts. Finally, six studies were selected. Results: The effect size of symptoms of COVID-19 was fever: $92 \%$ ( $\mathrm{ES}=0.92,95 \% \mathrm{CI} 0.79-1.06)$, cough: $73 \%$ ( $\mathrm{ES}=0.73,95 \% \mathrm{CI} 0.59-0.88)$, headache: $8 \%$ (ES $=0.8,95 \% \mathrm{CI} 0.06-0.22)$, myalgia $13 \%(\mathrm{ES}=0.13,95 \% \mathrm{CI} 0.01-0.27)$ and nasal congestion $22 \%(\mathrm{ES}=0.22$, 95\% CI 0.06-0.39). The following recommendations are appropriate during COVID-19 for dental emergency management: personal protective equipment and hand cleanliness practices, personal protective equipment (PPE), preprocedural mouth rinse, single-use (disposable), cone-beam computed tomography (CBCT) and periapical (PA) radiography, Rubber dam, sodium hypochlorite for root canal irrigation, disinfect inanimate surfaces, ultrasonic scaling instruments and airborne infection isolation. Conclusion: Fever should be used as the first sign in the diagnosis; dentists should measure the fever of all patients at the time of arrival and before any procedure and then ask about other symptoms.
\end{abstract}

Keywords: Dental Care; SARS-CoV-2; Coronavirus; COVID-19. 


\section{Introduction}

Since the development of the novel 2019 coronavirus infection (2019-nCoV) in Wuhan, China, in December 2019, it has rapidly advanced into a public health crisis and spread to several other countries [1]. Corona Virus Disease (COVID-19) [2] was declared by the World Health Organization (WHO) on February 11, 2020. The previously temporarily named 2019-nCoV has now been renamed severe acute respiratory syndrome coronavirus-2, SARS-CoV-2 [3] by the international committee on virus taxonomy. Reported early studies transmitted from animals to humans, but studies have illustrated through droplets or direct contact, human-to-human transmission of the covid-19 [4,5]. So far, the 2019-nCoV has affected more than 43,150,456 reported cases, according to a new report from the University of Johns Hopkins (JHU) center for science and engineering in systems (CSSE) (October 26, 2020) (Figure1).

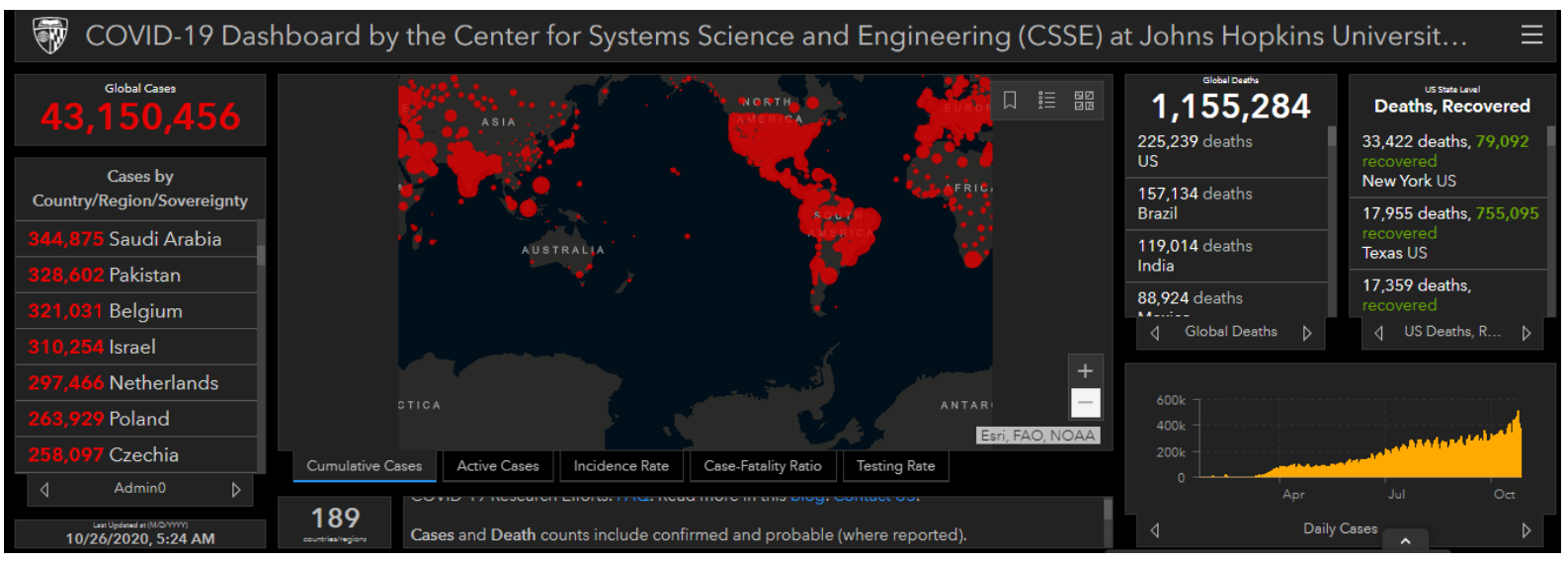

Figure1. Screenshot of global COVID-19 statistics by the Johns Hopkins University (JHU) Center for Systems Science and Engineering (CSSE). https://coronavirus.jhu.edu/map.html.

Dentists are at high risk and may be carriers of the disease, according to several published reports on the health care provided by SARS-CoV-2 [5,6]. Therefore, appropriate measures should be taken to identify, prevent, and manage this crisis [7]. It can attribute these risks to the type of dental intervention. In addition, if not cautious enough, patients will be exposed to contaminants at the dental clinic [8]. Given the global statistics and the fact that this disease is evolving day by day, dental procedures should be aimed at recognizing the symptoms, identifying suspected patients, infected patients, as well as knowledge of epidemiology and how to perform dental procedures to be done. So far, studies have not been conducted to examine the symptoms, how dentists are involved, epidemiology in dental offices, so other studies were used to present the study to evaluate the symptoms and epidemiology in the meta-analysis, so that at least useful solutions for dentists can be provided with better understanding.

The present systematic literature review and meta-analysis aim were to evaluate the epidemiological evidence, symptoms, and transmission routes of Coronavirus Disease 19 for clinical dental care.

\section{Material and Methods}

Search Method

The PubMed, Embase, ISI, Scopus, Medicine have been used to search for articles until October 2020. EndNote X9 software used to manage electronic resources. PubMed Searching was performed using mesh terms: ("severe acute respiratory syndrome coronavirus 2" [Supplementary Concept]) OR "COVID-19" 
[Supplementary Concept]) AND "Dental Care"[Mesh]) AND ("Epidemiology"[Mesh] OR "epidemiology" [Subheading])) OR "Prevalence"[Mesh]) AND ("Diagnosis"[Mesh] OR "diagnosis" [Subheading $]$ OR "Signs and Symptoms"[Mesh])) AND "Fever"[Mesh]) AND "Cough"[Mesh]) AND "Respiration"[Mesh]) AND "Headache"[Mesh]) AND "Dental Health Services"[Mesh].

The inclusion criteria were randomized controlled trials, controlled clinical trials, prospective and retrospective cohort studies, and cross-sectional studies. In vitro studies, case reports, case studies, and reviews were excluded from the present article.

Quality, Data Extraction and Statistical Analyses Methods

The Newcastle-Ottawa score was used to assess the non-RCT studies included in the present systematic review and meta-analysis [9]. The scale scores for low risk was 1 and for high and unclear risk was 0 , scale scores range from 0 to 8 , and a higher score means higher quality for data extraction, two reviewers blind and independently extracted data of studies that included. The effect size of symptoms with a confidence interval (CI) of 95\%, the random effect model, the REML method were calculated. In order to deal with potential heterogeneity, random effects were used, and I 2 showed heterogeneity. 2 values above $50 \%$ signified moderate-to-high heterogeneity. The Meta-analysis was evaluated using the statistical software Stata/MP v.16 (The fastest version of Stata).

\section{Results}

In the initial search with keywords, 41 articles were found. In the first step of selecting studies, 40 studies were selected to review the abstracts. Then, studies that did not meet the inclusion criteria were excluded from the study. In the second step, the full text of 25 studies was reviewed. Finally, six studies were selected (Figure 2).

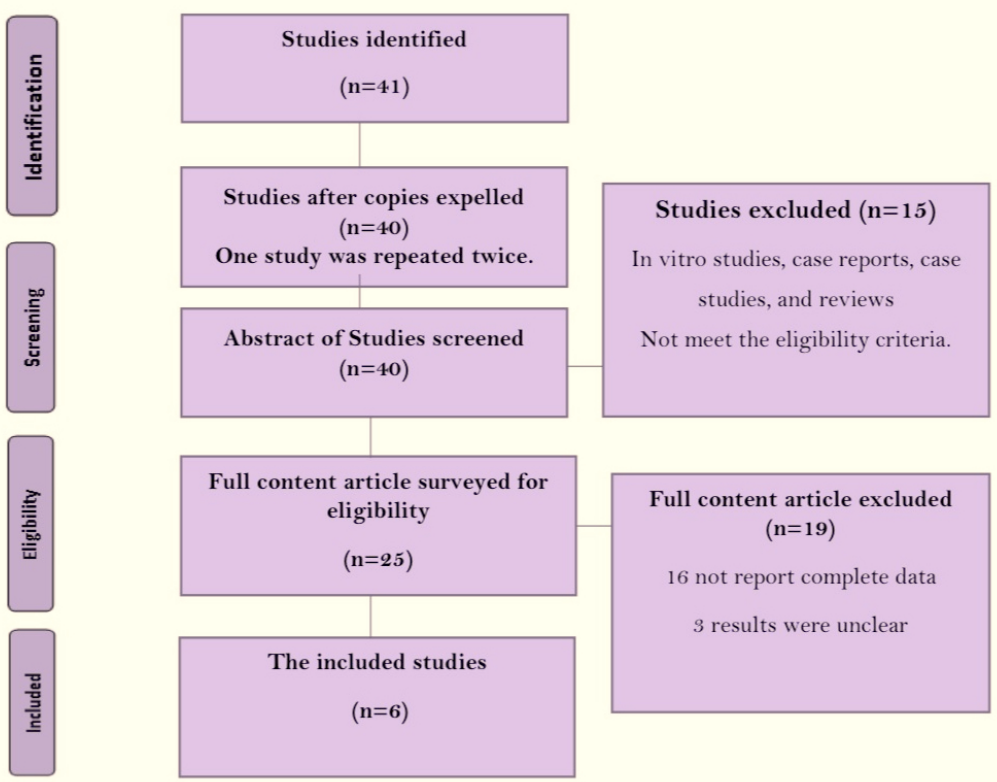

Figure 2. Flow chart.

In various ways, COVID-19 affects various people. Most people are infected with mild to moderate disease and recover without hospitalization. Fever, cough, tiredness, and less common symptoms are the most 
common symptoms: pains and aches, diarrhea, sore throat, conjunctivitis, headache, loss of taste or smell, skin rash, or finger toe discoloration. Moreover, most importantly, serious symptoms need special attention: shortness of breath or trouble breathing, pain, or pressure in the chest, lack of voice or movement.

A total of 6 studies were included in the present article, with 437 patients (Table 1). The symptoms of COVID-19 was fever: 92\% (ES = 0.92, 95\% CI 0.79-1.06), cough: 73\% (ES = 0.73, 95\% CI 0.59-0.88), headache: $8 \%(\mathrm{ES}=0.8,95 \% \mathrm{CI} 0.06-0.22)$, myalgia $13 \%(\mathrm{ES}=0.13,95 \% \mathrm{CI} 0.01-0.27)$ and nasal congestion $22 \%(\mathrm{ES}=$ 0.22, 95\% CI 0.06-0.39) (Figures 3 to 7 ).

Table 1. Details of selected studies.

\begin{tabular}{|c|c|c|c|c|c|c|c|}
\hline \multirow[t]{2}{*}{ Studies } & \multirow{2}{*}{$\begin{array}{l}\text { Study } \\
\text { Design }\end{array}$} & \multirow{2}{*}{$\begin{array}{c}\text { Number of } \\
\text { Patients }\end{array}$} & \multirow{2}{*}{$\begin{array}{c}\text { Case-fatality } \\
\text { Ratio }\end{array}$} & \multicolumn{2}{|c|}{ Sex } & \multirow{2}{*}{$\begin{array}{c}\text { Mean of } \\
\text { Age }\end{array}$} & \multirow{2}{*}{$\begin{array}{c}\text { Quality } \\
\text { Assessment } \\
\text { Score }\end{array}$} \\
\hline & & & & Male & Female & & \\
\hline Chang et al. $[10]$ & Retrospective & 13 & $0.0 \%$ & $77.0 \%$ & $23.0 \%$ & 34.8 & 13 \\
\hline Huang et al. [ $\left[\begin{array}{ll}1 & 1\end{array}\right]$ & Retrospective & 41 & $14.6 \%$ & $73.0 \%$ & $27.0 \%$ & 49.7 & 13 \\
\hline Wang et al. [12] & Prospective & 138 & $4.3 \%$ & $54.3 \%$ & $45.7 \%$ & 55.8 & 13 \\
\hline Chen et al. [13] & Retrospective & 99 & $11.0 \%$ & $68.0 \%$ & $32.0 \%$ & 56.0 & 12 \\
\hline Liu et al. [14] & Retrospective & 137 & $11.7 \%$ & $44.5 \%$ & $55.5 \%$ & 56.9 & 10 \\
\hline Zhang et al. [15] & Retrospective & 9 & $0.0 \%$ & $55.6 \%$ & $44.4 \%$ & 36.0 & 10 \\
\hline
\end{tabular}

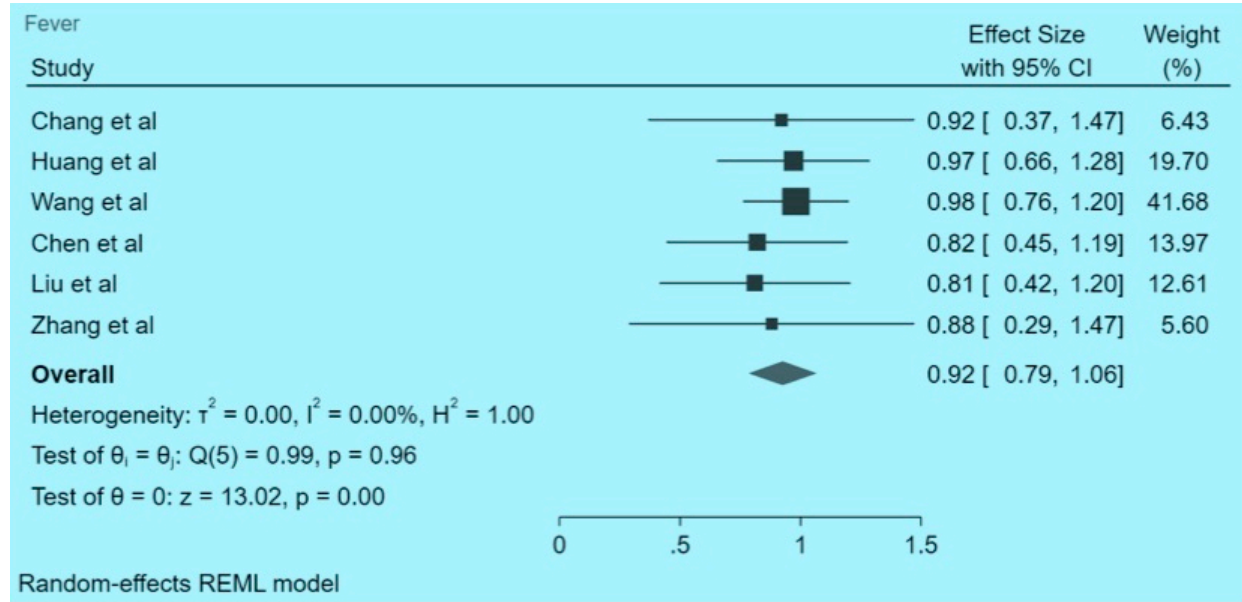

Figure 3. Forest plot showed the effect size of fever. (Effect Size = Mean, Standard Errors).

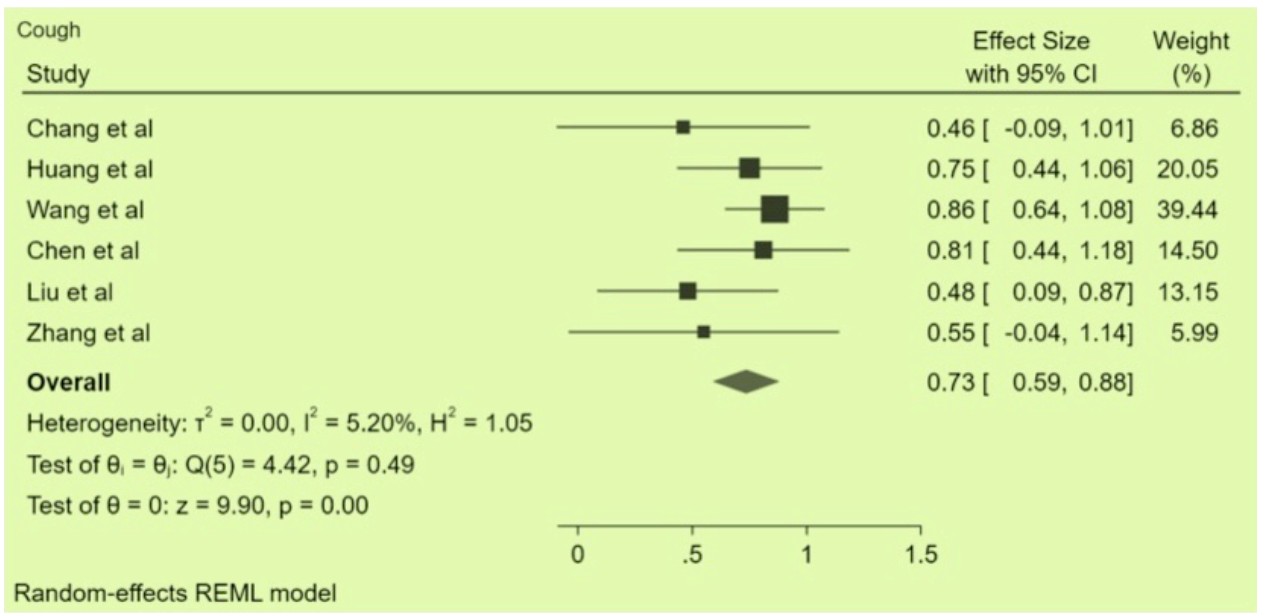

Figure 4. Forest plot showed the effect size of cough. (Effect Size = Mean, Standard Errors). 


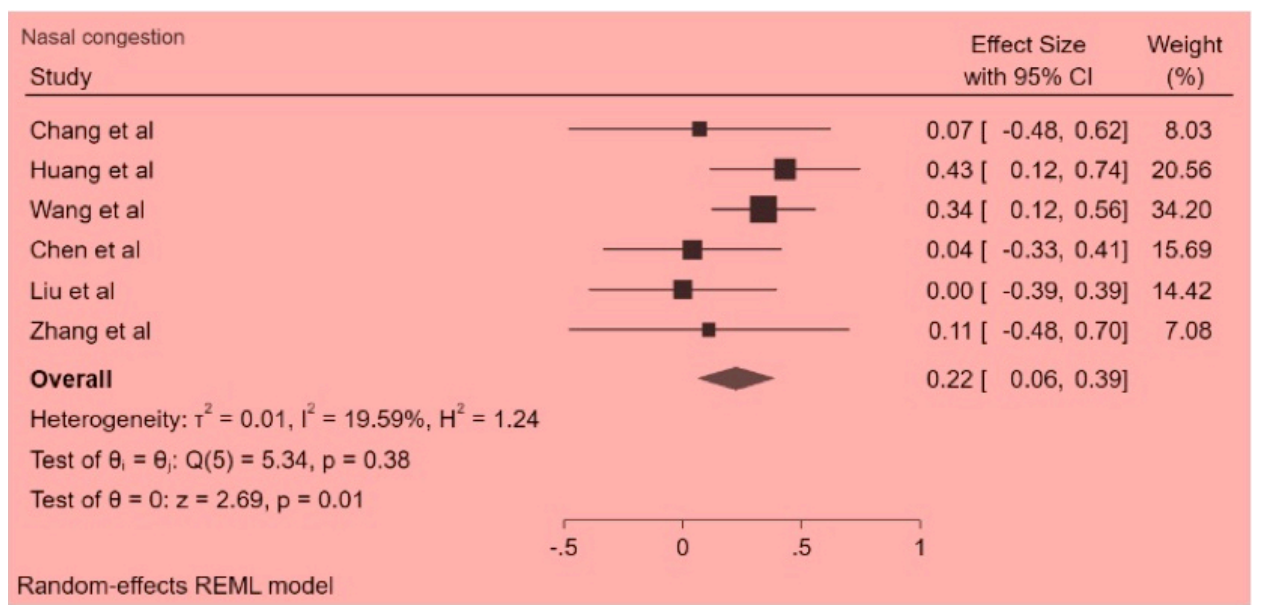

Figure 5. Forest plot showed the effect size of nasal congestion. (Effect Size = Mean, Standard Errors).

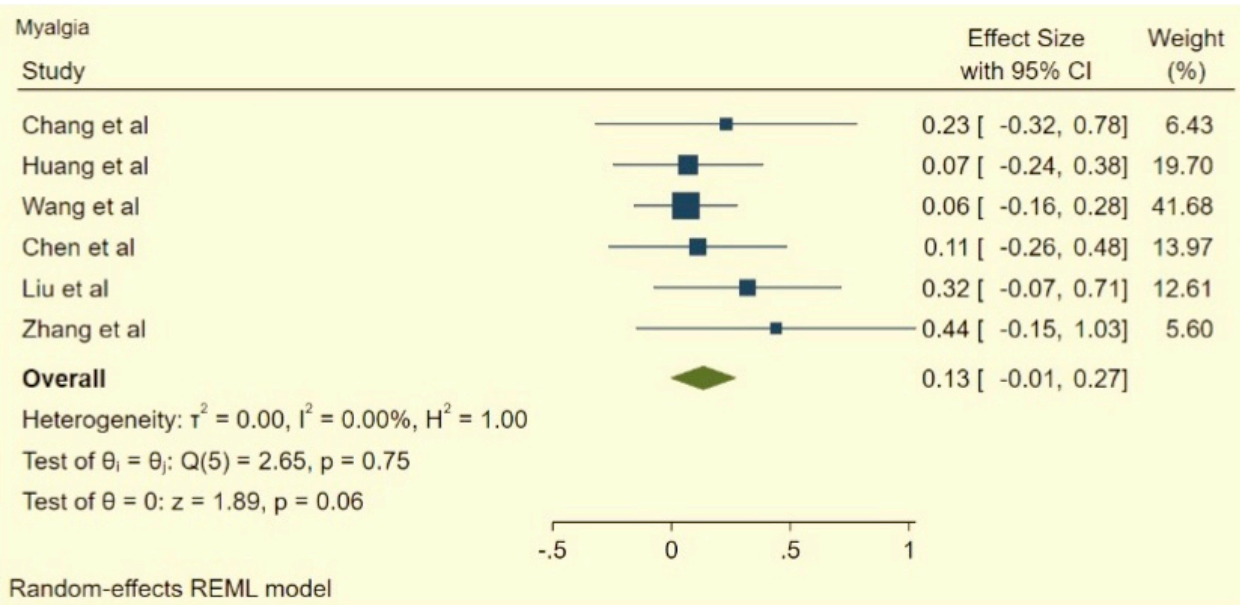

Figure 6. Forest plot showed the effect size of myalgia. (Effect Size = Mean, Standard Errors).

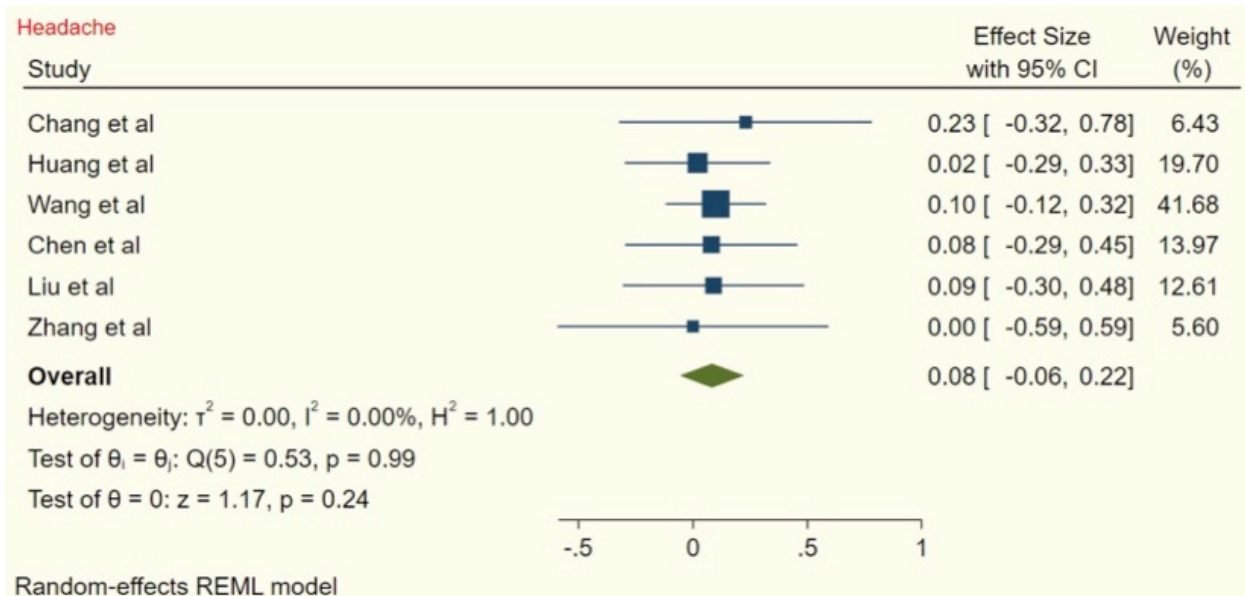

Figure 7. Forest plot showed the effect size of the headache. (Effect Size = Mean, Standard Errors).

A funnel plot showed a publication bias (Figure 8). About 92\% of patients have a fever. As a result, patients' fever should be checked in dental care before any procedure, then ask patients for other symptoms. It 
should be noted that some patients are carriers and have only mild symptoms (carriers). It takes an average of 5-6 days for a person to get the virus to show symptoms, but it can take up to 14 days.

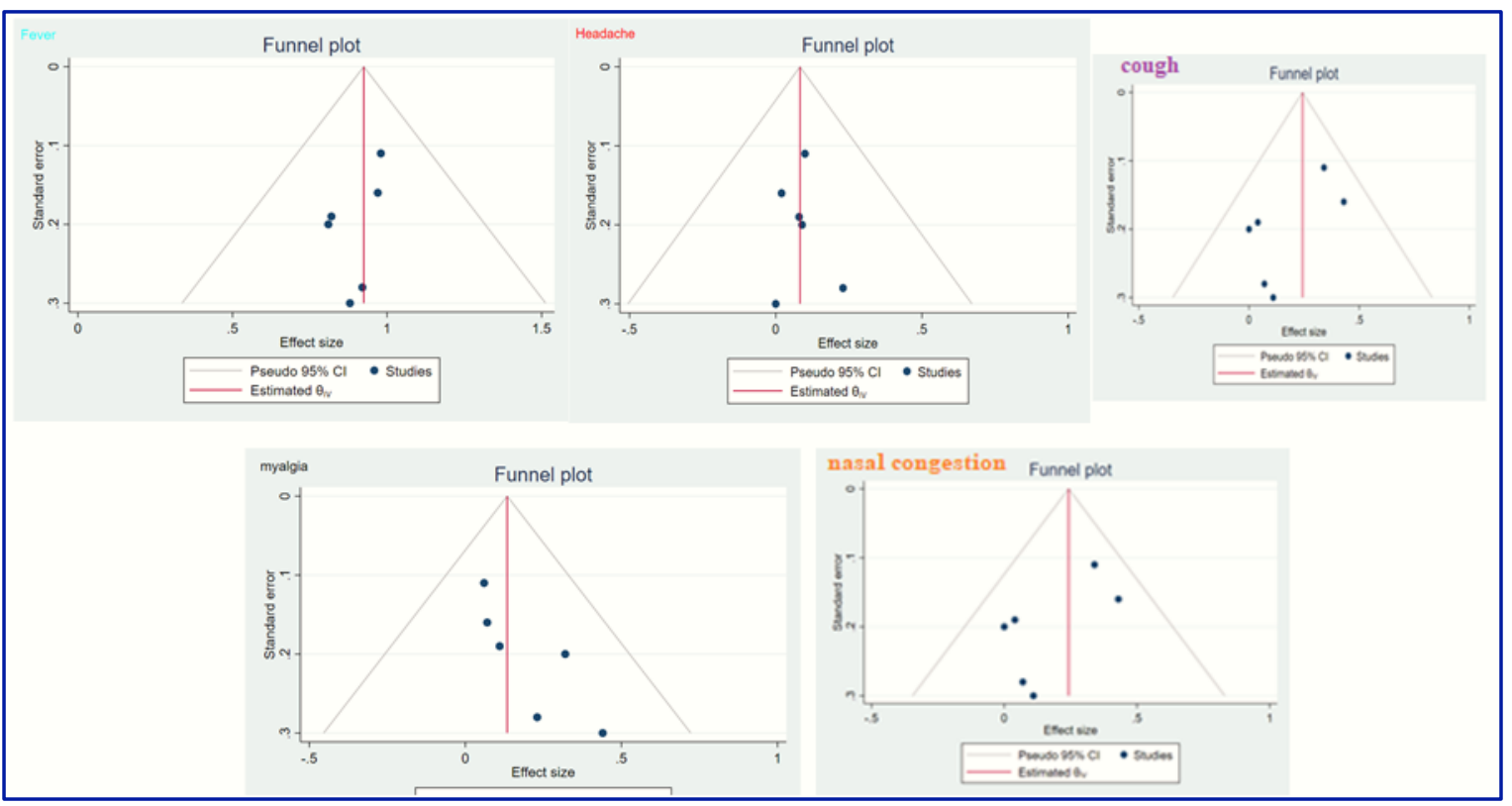

Figure 8. Funnel plot showed the publication bias of studies.

Bias Assessment

According to NOS tools, three studies had a total score of $5 / 8$, two studies had a total score of $4 / 8$, and one study had a total score of $6 / 8$. This outcome showed scores ranged from 6 to 8 were low risk of bias or high quality, and 3 to 5 were moderate risk of bias (Table 2 ).

Table 2. Risk of bias assessment.

\begin{tabular}{lcccc}
\hline \multicolumn{1}{c}{ Studies } & Selection (4 Scores) & Comparability (1 Score) & Exposure (3 Scores) & Total Score \\
\hline Chang et al. [10] & 1 & 1 & 2 & 4 \\
Huang et al. [11] & 1 & 1 & 3 & 2 \\
Wang et al. [12] & 1 & 1 & 2 & 5 \\
Chen et al. [13] & 2 & 1 & 3 & 5 \\
Liu et al. [14] & 1 & 1 & 3 & 6 \\
Zhang et al. [15] & 2 & & 5 \\
\hline
\end{tabular}

Transmission Routes

1) Human to human by respiratory droplets $[6,16]$.

2) Human to human by contact $[6,16]$.

3) Cough or sneezing by a carrier (about $6 \mathrm{ft}$ ) [6].

4) Contact with an infected person [16].

5) Salivary particles, aerosol, and fomites [17-19].

According to the mentioned transmission routes, COVID-19 can spread to dental offices. As a result, hands should be washed regularly, all equipment and surfaces should be disinfected regularly, and personal protective equipment and preferably disposable items should be used.

Patient Screening 
Identification of suspected patients or carriers of Covid-19:

1) Emergency dental care: using negative pressure rooms or rooms for isolation of airborne infection (AII).

2) Urgent dental care: pharmacological and phone tracking with video treatment.

3) Elective dental care: postpone of treatment for 14 days or/and initial screening via telephone.

\section{Patient Assessment}

As soon as the patient is scheduled for dental treatment, a comprehensive medical history, screening questionnaire for COVID-19, and true emergency questionnaire should be completed.

Items of COVID-19 screening questionnaire:

1. You or any household member have traveled through areas with known cases of covid-19 in the past 14 days?

2. Have you or a household member contacted in the past 14 days with a known COVID-19 patient?

3. Have you or any household member has a history of biological martial exposure to COVID-19?

4. Do you have any history of fever over the last 14 days?

5. Did you have any symptoms such as cough, trouble berating, diarrhea, nausea, and body cage, loss of smell, or loss of taste in the last 14 days?

6. Do you have uncontrolled dental or oral plans, infection, bleed ingot trauma, or swelling to your mouth?

\section{Discussion}

The present review showed that dentists or dental assistants should examine the patient's condition and fever upon arrival. According to the American Dental Association's recommendations, dentists can decide to provide or delay dental care after seeing the condition of the teeth. In case of an outbreak, dental priority is with emergency treatments [20].

The following recommendations are appropriate during COVID-19 for dental emergency management: personal protective equipment and hand cleanliness practices, personal protective equipment (PPE), preprocedural mouth rinse, single-use (disposable), cone-beam computed tomography (CBCT) and periapical (PA) radiography, rubber dam, sodium hypochlorite for root canal irrigation, disinfect inanimate surfaces, ultrasonic scaling instruments, and airborne infection isolation. Global precautions should be taken to minimize the prevalence of COVID- 19 .

Also, the precautionary measures examined in this study should be taken by dentists to prevent infection. Endodontists are in a special position as they can be called for in suspected or known patients with COVID-19 to treat and manage severe odontogenic pain, swelling, and dental alveolar trauma [21,22].

Dentists need to consider each patient as a carrier and take all patient precautions. Adequate training should be given to dentists and all persons involved in dental care. Also, by educating people in the community and avoiding unnecessary visits to dental offices, preventing further transmission of this virus and its spread is possible. Lack of studies in dentistry, asymptomatic people, small sample size, and the absence of a control group in some studies can be considered the limitations of the present study. The strengths of the present study are that the cohort studies have been selected for medium to high quality.

\section{Conclusion}


Fever should be used as the first sign in the diagnosis; dentists should measure all patients' fever at the time of arrival and before any procedure and then ask about other symptoms. The use of prevention and treatment protocols can be considered important for dentists and dental patients. Recommended, retrospective and prospective research is recommended in dental care associated with COVID-19, and more studies are requested in the future.

\section{Authors' Contributions}

\begin{tabular}{|c|c|c|}
\hline AA & (iD) https://orcid.org/0000-0001-9416-808X & $\begin{array}{l}\text { Conceptualization, Methodology, Formal Analysis, Investigation, Data Curation, Writing - } \\
\text { Original Draft, Writing - Review and Editing and Visualization. }\end{array}$ \\
\hline PM & (iD) https://orcid.org/0000-0002-6857-6482 & Methodology, Writing - Original Draft and Writing - Review and Editing. \\
\hline SJ & https://orcid.org/0000-0001-5196-0296 & Validation, Writing - Original Draft and Writing - Review and Editing. \\
\hline ZSTJ & (i) https://orcid.org/0000-0001-7908-0004 & Validation, Writing - Original Draft and Writing - Review and Editing. \\
\hline
\end{tabular}

\section{Financial Support}

None.

\section{Conflict of Interest}

The authors declare no conflicts of interest.

\section{Data Availability}

The data used to support the findings of this study can be made available upon request to the corresponding author.

\section{References}

[1] Schwartz DA, Graham AL. Potential maternal and infant outcomes from (Wuhan) coronavirus 2019-nCoV infecting pregnant women: lessons from SARS, MERS, and other human coronavirus infections. Viruses 2020; 12(2):194. https://doi.org/10.3390/v12020194

[2] Wei FF, Moradkhani A, Hemmati Hezaveh H, Miraboutalebi SA, Salehi L. Evaluating the treatment with favipiravir in patients infected by COVID-19: A systematic review and meta-analysis. IJSRDMS 2020; 2(3):87-91. https://doi.org/10.30485/IJSRDMS.2020.241494.1079

[3] Cheng VC, Wong SC, Chen JH, Yip CC, Chuang VW, Tsang OT, et al. Escalating infection control response to the rapidly evolving epidemiology of the Coronavirus disease 2019 (COVID-19) due to SARS-CoV-2 in Hong Kong. Infect Control Hosp Epidemiol 2020; 41(5):493-8. https://doi.org/10.1017/ice.2020.58

[4] Casaroto AR, Jamali J, Amini F, Talebzade Toranji M, Kayasöken G. Evaluation epidemiology, symptoms, and routes of COVID-19 for dental care: a literature review. IJSRDMS 2020; 2(2):37-41. https://doi.org/10.30485/IJSRDMS.2020.231680.1056

[5] Borges do Nascimento IJ, Cacic N, Abdulazeem HM, von Groote TC, Jayarajah U, Weerasekara I, et al. Novel coronavirus infection (COVID-19) in humans: a scoping review and meta-analysis. J Clin Med 2020; 9(4):941. https://doi.org/10.3390/jcm9040941

[6] Aponte Mendez M, Rivera Marval EK, Talebzade Toranji M, Amini F, Casaroto AR. Dental care for patients during the Covid-19 outbreak: a literature review. IJSRDMS 2020; 2(2):42-5. https://doi.org/10.30485/IJSRDMS.2020.232096.1058

[7] Baghizadeh Fini M. Transmission routes of SARS-CoV-2 in dentistry: a literature review. IJSRDMS 2020; 2(4):135137. https://doi.org/10.30485/ijsrdms.2020.252402.1088

[8] Alharbi A, Alharbi S, Alqaidi S. Guidelines for dental care provision during the COVID-19 pandemic. Saudi Dent J 2020; 32(4):181-6. https://doi.org/10.1016/j.sdentj.2020.04.001

[9] Wells GA, Shea B, O'Connell D, Peterson J, Welch V, Losos M, et al. The Newcastle-Ottawa Scale (NOS) for assessing the quality of nonrandomized studies in meta-analyses. 2011. Available from: http://www.ohri.ca/programs/clinical_epidemiology/oxford.asp. [Accessed on October 10, 2020].

[10] Chang D, Lin M, Wei L, Xie L, Zhu G, Cruz CS, et al. Epidemiologic and clinical characteristics of novel coronavirus infections involving 13 patients outside Wuhan, China. Jama 2020; 323(11):1092-3. https://doi.org/10.1001/jama.2020.1623

[11] Huang C, Wang Y, Li X, Ren L, Zhao J, Hu Y, et al. Clinical features of patients infected with 2019 novel coronavirus in Wuhan, China. Lancet 2020; 395(10223):497-506. https://doi.org/10.1016/So 140-6736(20)30183-5 
[12] Wang D, Hu B, Hu C, Zhu F, Liu X, Zhang J, et al. Clinical characteristics of 138 hospitalized patients with 2019 novel coronavirus-infected pneumonia in Wuhan, China. Jama 2020; 323(11):1061-9. https://doi.org/10.1001/jama.2020.1585

[13] Chen N, Zhou M, Dong X, Qu J, Gong F, Han Y, et al. Epidemiological and clinical characteristics of 99 cases of 2019 novel coronavirus pneumonia in Wuhan, China: a descriptive study. Lancet 2020; 395(10223):507-13. https://doi.org/10.1016/So140-6736(20)30211-7

[14] Liu K, Fang YY, Deng Y, Liu W, Wang MF, Ma JP, et al. Clinical characteristics of novel coronavirus cases in tertiary hospitals in Hubei Province. Chin Med J 2020; 133(9):1025-31. https://doi.org/10.1097/CM9.0000000000000744

[15] Zhang MQ, Wang XH, Chen YL, Zhao KL, Cai YQ, An CL, Lin MG, Mu XD. Clinical features of 2019 novel coronavirus pneumonia in the early stage from a fever clinic in Beijing. Zhonghua Jie He He Hu Xi Za Zhi 2020; 43(0):E013. https://doi.org/10.3760/cma.j.issn.1001-0939.2020.0013

[16] Nguyen T, Duong Bang D, Wolff A. 2019 novel coronavirus disease (COVID-19): paving the road for rapid detection and point-of-care diagnostics. Micromachines 2020; 11(3):306. https://doi.org/10.3390/mi 11030306

[17] To KK, Tsang OT, Yip CC, Chan KH, Wu TC, Chan JM, et al. Consistent detection of 2019 novel coronavirus in saliva. Clin Infect Dis 2020; 71(15):841-3. https://doi.org/10.1093/cid/ciaa 149

[18] Spagnuolo G, De Vito D, Rengo S, Tatullo M. COVID-19 outbreak: An overview on dentistry. Int J Environ Res Public Health 2020; 17(6):2094. https://doi.org/10.3390/ijerph17062094

[19] Coulthard P. Dentistry and coronavirus (COVID-19)-moral decision-making. Br Dent J 2020; 228(7):503-5. https://doi.org/10.1038/s41415-020-1482-1

[20] Farook FF, Nuzaim MN, Ababneh KT, Alshammari A, Alkadi L. Covid-19 Pandemic and challenges of dentistry: COVID-19 pandemic: oral health challenges and recommendations. Eur J Dent 2020; 14(Suppl 1):S165-S170. https://doi.org/10.1055/s-0040-1718641

[21] Darwish S. COVID-19 considerations in dental care. Dent Update 2020; 47(4):287-302. https://doi.org/10.12968/denu.2020.47.4.287

[22] List N. EPA's registered antimicrobial products for use against novel coronavirus SARS-CoV-2, the cause of COVID19. Washington, DC: United States Environmental Protection Agency; 2020. 